ISSN 1420-3049

www.mdpi.com/journal/molecules

Article

\title{
A New Benzofuran Derivative from Flemingia philippinensis Merr. et Rolfe
}

\author{
Hua Li ${ }^{1,2}$, Fengyan Zhai ${ }^{3}$, Meihua Yang ${ }^{1}$, Xiaowan $\mathrm{Li}^{4}$, Pingli Wang ${ }^{4}$ and Xiaojun Ma ${ }^{1,5, *}$ \\ 1 Institute of Medicinal Plant Development, Chinese Academy of Medical Sciences and \\ Peking Union Medical College, Beijing 100094, China \\ 2 Department of Food Science, Henan University of Technology, Zhengzhou 450001, Henan, China \\ 3 Department of Resource and Environment, Henan Institute of Science and Technology, \\ Xinxiang 453003, Henan, China \\ 4 Biology Technology Institute, Xinjiang Agricultural Vocational and Technical Institute, \\ Changji 831100, Xinjiang, China \\ 5 Guangxi Botanical Garden of Medicinal Plant, Nanning 530023, Guangxi, China \\ * Author to whom correspondence should be addressed; E-Mail: xjma@public.bta.net.cn; \\ Tel./Fax: +86-10-6281-9410.
}

Received: 16 April 2012; in revised form: 31 May 2012 / Accepted: 5 June 2012 /

Published: 25 June 2012

\begin{abstract}
A new prenylated benzofuran derivative, named flemiphilippinone A, was isolated together with ten known flavonoids from the roots of Flemingia philippinensis. Flemiphilippinone A was identified as (2S,3aS)-5-(1-hydroxy-3-(4-methoxyphenyl)propylidene)-2-(2-hydroxypropan-2-yl)-3a,7-bis(3-methylbut-2-en-1-yl)tetrahydrobenzofuran-4,6(2H,5H)-dione, and its structure was established by a combination of HR EIMS, ${ }^{1} \mathrm{H}-\mathrm{NMR},{ }^{13} \mathrm{C}-\mathrm{NMR}, \mathrm{HMQC}, \mathrm{HMBC}$ and NOESY spectra data.
\end{abstract}

Keywords: Flemingia philippinensis; flemiphilippinone A; flavonoids

\section{Introduction}

Early studies regarding the chemical constituents of Flemingia philippinensis have revealed the presence of flavonoids, steroids and triterpenes [1-3]. In our previous research work on F. philippinensis, flavonoids, flavonoid glycosides, anthraquinones and organic acids were isolated [4-6]. In continuation of our research on the medicinal plant $F$. philippinensis, we have performed a 
phytochemical investigation on the root of $F$. philippinensis, which has led to the isolation of a new compound named flemiphilippinone A (1). In addition, ten known flavonoids were identified as lupinifolin (2) [7], 6,8-diprenyleriodictyol (3) [8], genistein (4) [9], biochanin A (5) [10], prunetin (6) [11], 3'-O-methylorobol-7-O-glycoside (7) [12], luteoloside (8) [13], sissotrin (9) [14], prunetin $4^{\prime}$-O-glycoside (10) [15] and genistin (11) [15] on the basis of their UV, IR, EI MS, ${ }^{1} \mathrm{H}-\mathrm{NMR}$, ${ }^{13} \mathrm{C}-\mathrm{NMR}$ spectral data and by comparison of spectral values reported in the literature. All compounds (the chemical structures shown in Figure 1), except 4, 5 and 11, were isolated from F. philippinensis at the first time and compound 1 was a new compound.

Figure 1. The chemical structures of compounds 1-11.

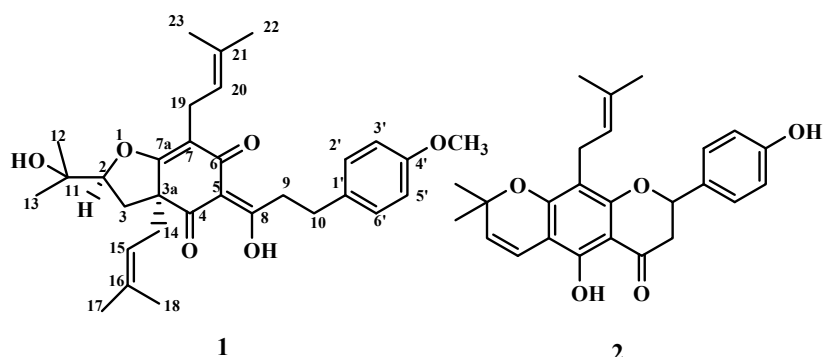<smiles>CC(C)=CCc1c(O)c(O)c2c(c1O)OC(c1ccc(O)c(O)c1)CC2=O</smiles><smiles>O=c1c(-c2ccc(O)cc2)coc2cc(O)cc(O)c12</smiles><smiles>COc1ccc(-c2coc3cc(O)cc(O)c3c2=O)cc1</smiles><smiles>COc1cc(O)c2c(=O)c(-c3ccc(O)cc3)coc2c1</smiles>

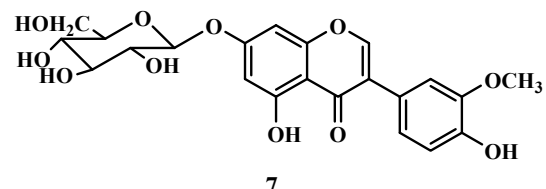

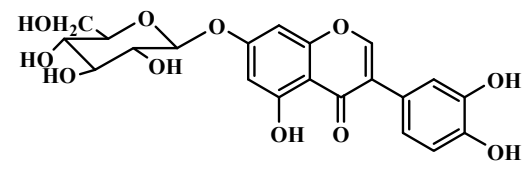

8

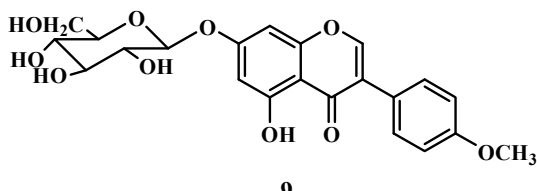<smiles>COc1cc(O)c2c(=O)c(-c3ccc(OC4OCCCCCCCC4O)cc3)coc2c1</smiles>

10

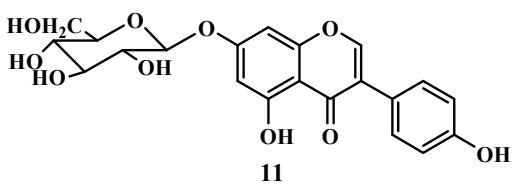

\section{Results and Discussion}

Flemiphilippinone A (1) was isolated as a light yellow oily liquid. The HR-EI-MS revealed a pseudomolecular ion peak at $\mathrm{m} / z 508.2788[\mathrm{M}]^{+}$, thus suggesting a molecular formula of $\mathrm{C}_{31} \mathrm{H}_{40} \mathrm{O}_{6}$ (calc. 508.2825). The ${ }^{1} \mathrm{H}-\mathrm{NMR}$ spectrum (Table 1) established the presence of four aromatic protons $\left(\delta 7.19\right.$ and 6.82). Two doublet proton signals at $\delta 7.19\left(2 \mathrm{H}, \mathrm{d}, J=8.5 \mathrm{~Hz}, \mathrm{H}-2^{\prime}, 6^{\prime}\right)$ and $\delta 6.82(2 \mathrm{H}, \mathrm{d}$, $\left.J=8.5 \mathrm{~Hz}, \mathrm{H}-3^{\prime}, 5^{\prime}\right)$ were correlated with ${ }^{13} \mathrm{C}$ signals at $130.4\left(\mathrm{C}-2^{\prime}, 6^{\prime}\right)$ and $115.6\left(\mathrm{C}-3^{\prime}, 5^{\prime}\right)$, respectively, in the $\mathrm{HMQC}$ spectrum, indicating the presence of an $\mathrm{AA}^{\prime} \mathrm{BB}^{\prime}$ system in a benzene ring. 
The signal at $\delta 3.77(3 \mathrm{H}, \mathrm{s})$ was correlated to the carbon signal at $\delta 158.0\left(\mathrm{C}-4^{\prime}\right)$ in HMBC spectrum (shown in Figure 2) and correlated to $\mathrm{H}-3^{\prime}, 5^{\prime}$ in NOE spectrum, revealed a methoxy group was substituted at $\mathrm{C}-4^{\prime}$ of benzene ring. Two protons at $\delta 2.92(1 \mathrm{H}, \mathrm{m})$ and $\delta 2.85(1 \mathrm{H}, \mathrm{m})$ related with $\delta$ 31.0 (C-10) shown in HMQC spectrum, and which related with $\delta 198.2$ (C-8), 40.0 (C-9), 133.3 (C-1') and $113.7\left(\mathrm{C}-2^{\prime}, 6^{\prime}\right)$, suggesting that a 4-methoxy-substituted phenmethyl group was present. What's more, two protons on the methylene group (C-9) correlated to $\delta 31.0$ (C-10) and 133.3 (C-1'), respectively, in the HMBC spectrum, indicating that the compound contained a 4-methoxy-substituted phenylethyl fragment, corresponding with the molecular weight of 121 and 135 in mass spectrum. In the HMBC spectrum, the signal at $\delta 18.84(-\mathrm{OH}, \mathrm{s})$ was correlated with the carbon signals at $\delta 106.5$ (C-7), 192.3 (C-6), 198.2 (C-8) and 40.0 (C-9), indicating that the hydroxyl at $\delta 18.84$ at low magnetic field connected with a six-membered ring, neighboring two adjacent ketones, and substituted at C-8, which is a structure similar to that of the prenylated benzophenone compound garciniaone $[16,17]$. What more, C-9 was correlated to C-8 according to the relations between H-9 and other carbons.

Figure 2. Selected HMBC (H-C) of compound 1.

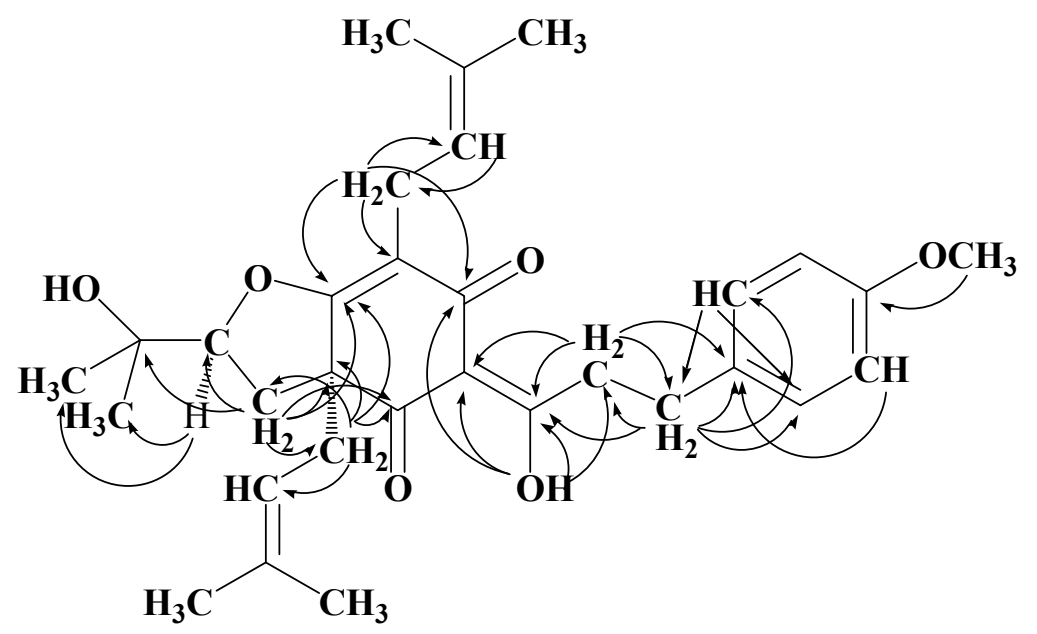

In the structure of this compound, two 3-methylbut-2-en-1-yl groups were was identified by the following ${ }^{1} \mathrm{H}-\mathrm{NMR}$ signals at $\delta 3.10(1 \mathrm{H}, \mathrm{m}, \mathrm{H}-19), 3.00(1 \mathrm{H}, \mathrm{dd}, J=7.5,14.5 \mathrm{~Hz}, \mathrm{H}-19), 5.11(1 \mathrm{H}, \mathrm{t}$, $J=7.5 \mathrm{~Hz}, \mathrm{H}-20), 1.72(3 \mathrm{H}, \mathrm{s}, \mathrm{H}-22)$ and $1.68(3 \mathrm{H}, \mathrm{s}, \mathrm{H}-23)$, and corresponding ${ }^{13} \mathrm{C}$ signals at $\delta 21.5$ (C-19), 121.5 (C-20), 17.8 (C-22), 17.8 (C-23), respectively, assigned by the HMQC spectrum. The HMBC data indicated that C-7 was substituted by a 3-methylbut-2-en-1-yl group due to the correlation between H-19 and $\delta 107.3$ (C-5), 192.3 (C-6) and 175.1 (C-4). The presence of another 3-methylbut-2-en-1-yl group was confirmed by the ${ }^{1} \mathrm{H}-\mathrm{NMR}$ signals at $\delta 2.50(1 \mathrm{H}, \mathrm{dd}, J=8.0,14.0 \mathrm{~Hz}$, H-14), 2.39 (1H, dd, $J=7.5,14.0 \mathrm{~Hz}, \mathrm{H}-14), 4.96(1 \mathrm{H}, \mathrm{t}, J=7.5 \mathrm{~Hz}, \mathrm{H}-15), 1.66(3 \mathrm{H}, \mathrm{s}, \mathrm{H}-17)$ and $1.52(3 \mathrm{H}, \mathrm{s}, \mathrm{H}-18)$. According to the correlation between $\mathrm{H}-15$ and $\delta 60.6(\mathrm{C}-3 \mathrm{a}), 175.1(\mathrm{C}-4)$ and 195.7 (C-7a), C-3a was substituted by the prenyl group. All the assignments of ${ }^{1} \mathrm{H}-$ and ${ }^{13} \mathrm{C}-\mathrm{NMR}$ data for the compound were achieved by HMQC and HMBC experiments.

The signal $\delta 4.51(1 \mathrm{H}, \mathrm{dd}, J=6.5,10.0 \mathrm{~Hz}, \mathrm{H}-2)$ was split into a dd peak by $2.16(2 \mathrm{H}, \mathrm{m}, \mathrm{H}-3)$ which correlated to $\delta 90.5$ (C-2), 60.6 (C-3a), 175.1 (C-4), 195.7 (C-7a), 71.2 (C-11) and 38.7 (C-14) in $\mathrm{HMBC}$ spectrum, indicating that $\mathrm{C}-2$ connected with $\mathrm{C}-3 \mathrm{a}$ through $\mathrm{C}-3$. Two single signals $\delta 1.33$ and 1.16 at $\mathrm{C}-11$, were correlated to $\delta 71.8(\mathrm{C}-11)$ and $90.5(\mathrm{C}-2)$. Moreover, $\mathrm{C}-7 \mathrm{a}(\delta$ 195.7) was 
linked to $\mathrm{C}-7$ ( $\delta$ 106.5) by double bond and C-7a connected with $\mathrm{C}-5$ ( $\delta 90.5)$ through an oxygen bridge. Beside the partial structures mentioned above, the molecular formula $\mathrm{C}_{31} \mathrm{H}_{40} \mathrm{O}_{6}$ requires a hydroxyl group which must be connected with $\mathrm{C}-11$, which was a quaternary carbon and chemical shift appeared at 71.8 in the low magnetic field.

Table 1. ${ }^{1} \mathrm{H}(500 \mathrm{MHz}),{ }^{13} \mathrm{C}(125 \mathrm{MHz})$ and $2 \mathrm{D}-\mathrm{NMR}(500 \mathrm{MHz})$ data of $\mathbf{1}$ in $\mathrm{CDCl}_{3}$.

\begin{tabular}{|c|c|c|c|c|c|}
\hline Position & $\delta_{\mathbf{H}} J(\mathbf{H z})$ & $\delta_{\mathbf{C}}$ & НМВС & COSY & NOE \\
\hline 2 & $4.51 \mathrm{dd}(6.5,10)$ & 90.5 & $\mathrm{C}-12,13$ & H-3 & H-3, 12, 13, 14 \\
\hline 3 & $2.16 \mathrm{~m}$ & 30.6 & C-2,3a, 4, 7a, 11, 14 & $\mathrm{H}-2$ & H-13 \\
\hline $3 a$ & & 60.6 & & & \\
\hline 4 & & 175.1 & & & \\
\hline 5 & & 107.3 & & & \\
\hline 6 & & 192.3 & & & \\
\hline 7 & & 106.5 & & & \\
\hline $7 \mathrm{a}$ & & 195.7 & & & \\
\hline $8(-\mathrm{OH})$ & $18.84 \mathrm{~s}$ & 198.2 & C-6, 7, 8, 9 & & \\
\hline \multirow[t]{2}{*}{9} & $3.18 \mathrm{~m}$ & 40.0 & $\mathrm{C}-7,8,10,1^{\prime}$ & & \\
\hline & $3.10 \mathrm{~m}$ & & & & \\
\hline \multirow[t]{2}{*}{10} & $2.92 \mathrm{~m}$ & 31.0 & $\mathrm{C}-8,9,1^{\prime}, 2^{\prime}, 6^{\prime}$ & & \\
\hline & $2.85 \mathrm{~m}$ & & & & \\
\hline $1^{\prime}$ & & 133.3 & & & \\
\hline $2^{\prime}$ & $7.19 \mathrm{~d}(8.5)$ & 113.7 & $\mathrm{C}-10,3^{\prime}, 4^{\prime}, 6^{\prime}$ & & \\
\hline $3^{\prime}$ & $6.82 \mathrm{~d}(8.5)$ & 129.4 & $\mathrm{C}-1^{\prime}, 4^{\prime}, 5^{\prime}$ & & $\mathrm{OCH}_{3}-4^{\prime}$ \\
\hline $4^{\prime}$ & & 158.0 & & & \\
\hline $5^{\prime}$ & $6.82 \mathrm{~d}(8.5)$ & 129.4 & $\mathrm{C}-1^{\prime}, 3^{\prime}, 4^{\prime}$ & & $\mathrm{OCH}_{3}-4^{\prime}$ \\
\hline $6^{\prime}$ & $7.19 \mathrm{~d}(8.5)$ & 113.8 & $\mathrm{C}-10,2^{\prime}, 4^{\prime}, 5^{\prime}$ & & \\
\hline 11 & & 71.2 & & & \\
\hline 12 & $1.33 \mathrm{~s}$ & 26.6 & $\mathrm{C}-2,11,13$ & & $\mathrm{H}-2$ \\
\hline 13 & $1.16 \mathrm{~s}$ & 23.8 & $\mathrm{C}-2,11,12$ & & $\mathrm{H}-2$ \\
\hline \multirow[t]{2}{*}{14} & $2.50 \mathrm{dd}(7.5,14.0)$ & 38.7 & $\mathrm{C}-3 \mathrm{a}, 4,7 \mathrm{a}, 3,15,16$ & $\mathrm{H}-15$ & $\mathrm{H}-2$ \\
\hline & $2.39 \mathrm{dd}(7.5,14.0)$ & & & & \\
\hline 15 & $4.96 \mathrm{t}(7.5)$ & 117.1 & C- 17,18 & $\begin{array}{c}\mathrm{H}-14,17, \\
18\end{array}$ & $\mathrm{H}-17$ \\
\hline 16 & & 137.0 & & & \\
\hline 17 & $1.66 \mathrm{~s}$ & 25.8 & C- $15,16,18$ & $\mathrm{H}-15$ & $\mathrm{H}-15$ \\
\hline 18 & $1.52 \mathrm{~s}$ & 17.8 & $\mathrm{C}-15,16,17$ & $\mathrm{H}-15$ & \\
\hline \multirow[t]{2}{*}{19} & $3.10 \mathrm{~m}$ & 21.5 & $\mathrm{C}-4,5,6,20,21$ & $\mathrm{H}-20,23$ & \\
\hline & $3.00 \mathrm{dd}(7.5,14.5)$ & & & & \\
\hline 20 & $5.11 \mathrm{t}(7.5)$ & 121.5 & $\mathrm{C}-19,22,23$ & $\mathrm{H}-19,23$ & $\mathrm{H}-23$ \\
\hline 21 & & 132.1 & & & \\
\hline 22 & $1.72 \mathrm{~s}$ & 17.8 & C-20, 21, 23 & & \\
\hline 23 & $1.68 \mathrm{~s}$ & 25.6 & C- $20,21,22$ & H-19, 20 & \\
\hline $4^{\prime}\left(-\mathrm{OCH}_{3}\right)$ & $3.77 \mathrm{~s}$ & 55.2 & C- $4^{\prime}$ & & $\mathrm{H}-3^{\prime}, 5^{\prime}$ \\
\hline
\end{tabular}

The stereochemistry of the proton at C-2 and butenyl group at C-3a in the structure was determined by the H-H correlations in the NOESY spectrum. The configurations of proton at C-2 was determined 
by the correlations of $\mathrm{H}-\mathrm{C}$ (2), Me (12), Me (13), and $\mathrm{H}-\mathrm{C}$ (14) which were assigned to be in an orientation on ground. According to the size of the connection groups at C-2, the stereochemistry was an $S$-configuration. In addition, the ROESY correlations of H-C (7) with H-C (19) and H-C (20), and $\mathrm{H}-7$ (21) with H-C (21) were assigned, indicating the stereochemistry of butenyl group at C-3a was also in an $S$-configuration. Therefore, the structure of flemiphilippinone A (1) was determined to be (2S,3aS)-5-(1-hydroxy-3-(4-methoxyphenyl)propylidene)-2-(2-hydroxypropan-2-yl)-3a,7-bis-(3methylbut-2-en-1-yl)tetrahydrobenzofuran-4,6(2H,5H)-dione.

\section{Experimental}

\subsection{General}

TLC was preformed with silica gel GF254 (Marine Chemical Industry Factory, Qingdao, China), and the spots were visualized by spraying with $10 \% \mathrm{H}_{2} \mathrm{SO}_{4}-\mathrm{EtOH}$ reagent, followed by heating. Column chromatography was performed using silica gel (Qingdao Haiyang Chemical Co., Ltd, Qingdao, China), reverse-phase C18 silica gel (50 $\mu \mathrm{m}$, Merck, city Germany) and Sephadex LH-20 (Amersham Pharmacia Biotech, Uppsala, Sweden). All reagents were analytical grade and water was distilled-twice. Optical rotation was measured on Perkin-Elmer 341 polarimeter (Fremont, CA, USA). UV spectra were measured with a Shimadzu UV-2550 visible spectrophotometer (Shimadzu, Japan). IR spectra were recorded on a NEXUS-470 FTIR (Nicolet, Jakarta Raya, Indonesia). All NMR experiments were performed on a Bruker DRX-500 spectrometer (Bruker, Switzerland) (500 MHz for $1 \mathrm{H}$ and $125 \mathrm{MHz}$ for 13C) equipped with $5 \mathrm{~mm}$ probe head (PADUL 13C). The chemical shifts were with $0.03 \%$ tetramethylsilane as an internal reference. About 3-10 mg samples were dissolved in $\mathrm{CDCl} 3$ or CD3OD $(0.5 \mathrm{~mL})$ to record the NMR spectra. EIMS and HR EIMS spectra were taken on an Auto Spec-ultima mass spectrometer (VG Co., English) at an ionization voltage of $70 \mathrm{eV}$.

\subsection{Plant Material}

The fresh roots were collected from Guangxi Botanical Garden of Medicinal Plant, Nanning, China in April 2007. A voucher specimen has been deposited in the Herbarium of the Institute of Medicinal Plant Development, Chinese Academy of Medical Science and Peking Union Medical College.

\subsection{Extraction and Isolation of Chemical Constituents}

The roots of $F$. philippinensis (30 kg) were dried, powdered and extracted three times with $75 \%$ EtOH (solid to liquid ratio $1: 10,24 \mathrm{~h}$, room temperature $20{ }^{\circ} \mathrm{C}$ ). After removal of the solvent by evaporation, the residue was suspended in water and defatted with petroleum ether. Then the aqueous layer was dried to afford the residue (723 g), which was subjected to the silica gel (200-300 mesh, $2 \mathrm{~kg}$ ) column chromatography using $\mathrm{CHCl}_{3}-\mathrm{MeOH}$ step-gradient elution (1:0-20:1-10:1-5:1-0:1, v/v) to yield five fractions (B1, B2, B3, B4 and B5). The fraction B1 (28 g) was subjected to a silica gel (200-300 mesh, $350 \mathrm{~g}$ ) column chromatography (CC) again using petroleum ether-acetone (P-EA, from 20:1 to 0:1). The fraction eluted with P-EA (20:1) was subjected to silica gel chromatography (eluted with $\mathrm{CHCl}_{3}: \mathrm{MeOH}$, from 1:0 to 5:1) and the part eluted by 20:1 was further separated by ODS-silica gel chromatography (eluted with 70-90\% $\mathrm{MeOH}$ ) and obtained the compound 1 (17 mg). 
One of fractions eluted with P-EA (15:1) was subjected to silica gel chromatography (eluted with $\left.\mathrm{CHCl}_{3} / \mathrm{MeOH}=20: 1\right)$ and Sephadex $\mathrm{LH}-20 \mathrm{CC}$ to yield one compound and two fractions which were further purified repeatedly by ODS-silica gel chromatography (eluted with $70-90 \% \mathrm{MeOH}$ ) to afford compound 2 (3 mg) and $3(0.4 \mathrm{mg})$, respectively. The fraction B2 (18 g) was subjected to silica gel (200-300 mesh, $300 \mathrm{~g}$ ) $\mathrm{CC}$ again using $\mathrm{CHCl}_{3}-\mathrm{MeOH}$ step-gradient elution (1:0-20:1-10:1) and the mixture of 5 and $6(31 \mathrm{mg})$ was obtained from the third part eluted with 10:1 through further separation using Sephadex LH-20 and ODS-silica gel (eluted with 70-80\% $\mathrm{MeOH}$ ) CC. The fraction B3 (12 g) was also subjected to a silica gel (200-300 mesh, $300 \mathrm{~g}) \mathrm{CC}$ using $\mathrm{CHCl}_{3}-\mathrm{MeOH}$ step-gradient elution (1:0-5:1). Compound $7(7 \mathrm{mg}), \mathbf{8}(6 \mathrm{mg})$ and the mixture 9 and $\mathbf{1 0}(23 \mathrm{mg})$ were obtained from the two fractions eluted with 20:1 and 10:1 by repeated CC on silica gel, followed by Sephadex LH-20 and ODS-silica gel (70\% MeOH). At the same time, compound 4 (102 mg) and 11 $(120 \mathrm{mg}$ ) were also obtained during the course of separation of the above compounds from fractions $\mathrm{B} 2$ and $\mathrm{B} 3$, respectively. The solvent system $\mathrm{CHCl}_{3}-\mathrm{MeOH}(2: 3)$ was used as the eluent on Sephadex LH-20 CC in the whole experiment.

\subsection{Flemiphilippinone A (1)}

Light yellow oily liquid $\left(\mathrm{CHCl}_{3}-\mathrm{MeOH}\right) ;[\alpha]_{D}^{10}:+0.050^{\circ}$ (c $\left.0.10, \mathrm{CHCl}_{3}\right) ; \mathrm{UV}(\mathrm{MeOH}) \lambda \max (\log$ Emax): 277 (0.59), 223 (1.40) nm. IR (KBr) v max: 3455, 2927, 2971, 1669, 1579, 1512, 1453, 1375, 1245, 1180, 1107, 1071, 1035, $826 \mathrm{~cm}^{-1} .{ }^{1} \mathrm{H}-$ and ${ }^{13} \mathrm{C}-\mathrm{NMR}$ : see Table 1. EI MS $m / z: 508[\mathrm{M}]^{+}(13)$, 439 (100), 383 (15), 305 (31), 278 (11), 249 (29), 177 (13), 121 (100), 69 (48). HR EIMS m/z: 508.2788 (calc. for $\mathrm{C}_{31} \mathrm{H}_{40} \mathrm{O}_{6}, 508.2825$ ).

\section{Conclusions}

Repeated column chromatography (including normal-phase silica gel, RP-silica gel and Sephadex LH-20) of the EtOH extract of the roots of $F$. philippinensis has led to the isolation of flemiphilippinone A (1), together with ten known flavonoids, including two prenylated flavanones, three simple isoflavones and five isoflavone glycosides, which were identified as lupinifolin (2), 6,8-diprenyleriodictyol (3), genistein (4), biochanin A (5), prunetin (6), 3'-O-methylorobol7-O-glycoside (7), luteoloside (8), sissotrin (9), prunetin 4'-O-glycoside (10) and genistin (11). The structure of the new compound 1 was determined by spectroscopic methods, including 1D NMR, 2D NMR and MS experiments, and the structures of the known compounds including $\mathbf{2} \sim \mathbf{1 1}$ were identified mainly by comparing their NMR data with those in the literature. In addition, it is worth mention that isoflavones and flavanones as two types of flavonoid compounds that could be considered chemomarkers of $F$. philippinensis at a higher level within species of the genus Flemingia. Flemiphilippinone A, was a novel compound, was firstly isolated from the Leguminosae, which potent activity and correlation with the antioxidant activity of $F$. philippinensis should be investigated further.

\section{Supplementary Materials}

Supplementary materials can be accessed at: http://www.mdpi.com/1420-3049/17/7/7637/s1. 


\section{Acknowledgements}

This research was financially supported by the Doctor Scientific Research Foundation of Henan University of Technology (No. 2009BS026), "12th Five-Year" National Science and Technology Support Program - Study on standardized planting for Southern Chinese herbs and comprehensive development of technologies for the bulk Chinese herbal medicines (2011BAI01B00) - Study on SOP optimization and standardization of products for three herbs contained Ilex kudingcha (2011BAI01B04) and National Natural Science Foundation of China (No.31071606 and 11079019). NMR spectra were provided by Beijing Institute of Microchemistry, Beijing 100091, China. MS spectra were provided by Department of Pharmacology, Institute of Materia Medica, Chinese Academy of Medical Sciences \& Peking Union Medical College (Beijing, China).

\section{References}

1. Chen, M.; Lou, S.Q.; Chen, J.H. Two isoflavones from Flemingia philippinensis. Phytochemistry 1991, 30, 3842-3844.

2. Chen, M.; Luo, S.Q.; Chen, J.H. Studies on the chemical constituents of Flemingia philippinensis. Acta Pharmacol. Sin. 1990, 26, 42-48.

3. Ahn, E.M.; Nakamura, N.; Akao, T.; Komatsu, K.; Qui, M.H.; Hattori, M. Prenylated flavonoids from Moghania philippinensis. Phytochemistry 2003, 64, 1389-1394.

4. Li, H.; Yang, M.H.; Miao, J.H.; Ma, X.J. Prenylated isoflavones from Flemingia philippinensis. Magn. Reson. Chem. 2008, 46, 1203-1207.

5. Li, H.; Yang, M.H.; Ma, X.J. Flavonoids from roots of Flemingia philippinensis. Chin. J. Chin. Mat. Med. 2009, 34, 724-726.

6. Li, H.; Yang, M.H.; Si, J.Y.; Miao, J.H.; Ma, X.J. Chemical constituents from roots of Flemingia philippinensis. Chin. Tradit. Herb Drugs 2009, 40, 512-516.

7. Chulabhorn, M.; Hunsa, P.; Somsak, R. Prenylated flavanones from Derris reticulata. Phytochemistry 1977, 45, 825-829.

8. Bonaventure, T.N.; Berhanu, M.A.; Etienne, D.; Helene, T.; Kouam, F. Geranylated and prenylated flavonoids from the twigs of Dorstenia mannii. Phytochemistry 1998, 48, 349-354.

9. Feng, J.; Xiang, C.; Liang, H. Chemical constituents of isoflavones from vine stems of Millettia nitita var. hirsutissima. Chin. J. Chin. Mat. Med. 2007, 32, 321-322.

10. Huang, S.Y.; Tu, P.F. Isolation and Identification of Isoflavones from Trifolium pratense. Acta Sci. Natur. Univ. Pekinensis 2007, 40, 544-549.

11. Deng, Y.R.; Wang, T.; He, Y.Z. Studies on chemical constituents of Caragana spinifera. Chin. J. Chin. Mat. Med. 2008, 33, 775-777.

12. Wang, Y.F.; Mu, T.H.; Chen, J.J.; Luo, S.D. Studies on Chemical Constituents from the Root of Polygonatum kingianum. Chin. J. Chin. Mat. Med. 2003, 28, 524-527.

13. Huang, M.Z.; Chen, H.S.; Liu, J.G.; Zhou, X.H.; Du, J.L.; Xiang, Z.B. Studies on the chemical constituents of Bidens bipinnata L. Acad. J. Second Military Med. Univ. 2006, 27, 888-891.

14. Tan, Y.X.; Sun, Y.H.; Chen, R.Y. Studies on chemical constituents in seeds of Cicer arietinum. Chin. J. Chin. Mat. Med. 2007, 32, 1650-1652. 
15. Tang, Y.P.; Lou, F.C.; Ma, W.; Wang, J.H.; Li, Y.F. Isoflavonoid glycosides from the pericarps of Sophora japonica. J. Chin. Pharm. Univ. 2001, 32, 187-189.

16. Derogis, P.B.; Martins, F.T.; Souza, T.C.; Moreira, M.E.; Souza, F.J.D.; Doriguetto, A.C.; Souza, K.R.; Veloso, M.P.; Santos, M.H. Complete assignment of the ${ }^{1} \mathrm{H}$ and ${ }^{13} \mathrm{C}-\mathrm{NMR}$ spectra of garciniaphenone and keto-enol equilibrium statements for prenylated benzophenones. Magn. Reson. Chem. 2008, 46, 278-282.

17. Hartati, S.; Wang, H.B.; Kardono, L.B.S.; Kosela, S.; Qin, G.W. Chemical constituents of Garcinia maingayii. Chin. J. Nat. Med. 2007, 5, 272-275.

Sample Availability: Samples of the flemiphilippinone A, lupinifolin, 6,8-diprenyleriodictyol, genistein biochanin A, prunetin, 3'-O-methylorobol-7- $O$-glycoside, luteoloside, sissotrin, prunetin $4^{\prime}-O$-glycoside and genistin are available from the authors.

(C) 2012 by the authors; licensee MDPI, Basel, Switzerland. This article is an open access article distributed under the terms and conditions of the Creative Commons Attribution license (http://creativecommons.org/licenses/by/3.0/). 